\title{
Solidaridad política con Chile desde el comunismo catalán: Partit Socialista Unificat de Catalunya y Joventut Comunista de Catalunya (1973-1980)
}

\author{
Political solidarity with Chile from catalonian communism: Unified Socialist Party of Catalonia \\ and Communist Youth of Catalonia (1973-1980)
}

\author{
Pedro Marchant Veloz*
}

\begin{abstract}
Resumen: El siguiente artículo abordará las dinámicas de la solidaridad política desarrolladas por el comunismo catalán con Chile entre 1973 y 1980, centrado en el Partit Socialista Unificat de Catalunya y la Joventut Comunista de Catalunya. Se destacarán las posturas internacionalistas, la influencia del paso de la clandestinidad a la legalidad del comunismo catalán y las diversas acciones de solidaridad desarrolladas durante el contexto estudiado.
\end{abstract}

Palabras claves: Solidaridad política, internacionalismo, dictadura chilena, Chile, Cataluña, comunismo.

Abstract: The next article will address the dynamics of political solidarity developed by the Catalan communism and Chile in the years 1973 to 1980, focusing on the Unified Socialist Party of Catalonia and the Communist Youth of Catalonia. The article will highlight various internationalist stances, the influence of the passage from clandestinity to legality of the Catalan communism and the numerous solidarity actions developed in the analyzed context.

Keywords: Political solidarity, Internationalism, chilean dictatorship, Chile, Catalonia, Communism.

Recibido: 8 abril 2019 Aceptado: 7 junio 2019

\section{Introducción}

El desarrollo de la dictadura de Pinochet en Chile tuvo un impacto directo en el comunismo catalán, el que se diferenciaba internamente entre las posturas eurocomunistas, siguiendo la línea de Santiago Carrillo en el Partido Comunista de España (PCE), y las más cercanas a la esfera soviética. Esto se demostró a partir del golpe de Estado y el fin del gobierno de la Unidad Popular, hitos que impulsaron una serie de manifestaciones y acciones de solidaridad política enmarcadas en las ideas internacionalistas, especialmente entre 1973 y 1980, años de clandestinidad comunista en Chile, España y Cataluña,

\footnotetext{
* Chileno. Licenciado en Historia, Licenciado en Educación Media con mención en Historia, Profesor de Educación Media con mención en Historia y Geografía y Magíster en Ciencia Política de la Universidad de Chile. Máster en Historia Contemporánea y Mundo Actual de la Universidad de Barcelona. Este artículo se desarrolló durante los estudios de máster en la Universidad de Barcelona, financiado por la Comisión Nacional de Investigación Científica y Tecnológica (CONICYT), Programa Formación de Capital Humano Avanzado, Becas Chile Magíster en el Extranjero/2017 - 73180315, agradeciendo el apoyo económico. Correo: pedro_marchant@outlook.com
} 
modificada en estos últimos casos tras la muerte de Franco y la legalización en 1977 del Partit Socialista Unificat de Catalunya (PSUC) y su sección juvenil, la Joventut Comunista de Catalunya (JCC).

En esta lógica, el objetivo de este artículo es explicar los mecanismos de acción del comunismo catalán en el ámbito de la solidaridad política chilena, así como las posturas internas -especialmente durante los congresos del PSUC y la JCC- respecto a cómo entender esta relación internacional, enmarcado en el primer septenio de la dictadura de Pinochet $(1973$ - 1980). En específico, se analizarán las diversas manifestaciones de apoyo, configuradas desde la comprensión interna de solidaridad, los cambios respecto a este tema y el contexto de legalización de comunismo catalán.

Los estudios relacionados con el exilio chileno y las redes de solidaridad en España han apuntado a diversos objetivos respecto a cómo se configuraron estas acciones. Se ha destacado la importancia de la llegada de exiliados chilenos posterior a la muerte de Franco y la transición democrática (1976-1982), centrada en los partidos de izquierda (Partido Socialista Obrero Español [PSOE] y el PCE), el peso de las divisiones internas dentro del socialismo chileno como configurador de las acciones de los exiliados, la influencia del eurocomunismo a nivel general y la crisis del marxismo en el socialismo internacional, representando a España, especialmente, dentro de la escena de la renovación socialista junto a Francia e Italia. Del mismo modo, la influencia de elementos culturales y políticos comunes entre los exiliados chilenos y la realidad española, generando un acercamiento paulatino de los expatriados a la realidad hispana, en concordancia con la duración del exilio por la permanencia de Pinochet en el poder en Chile.

Otros trabajos han indagado el rol de diversos actores políticos españoles en apoyo a la democratización chilena y el respeto a los derechos humanos: partidos, sindicatos y organizaciones no gubernamentales. A nivel de partidos, destacaron los cambios de acción entre los últimos años del franquismo y expresiones más abiertas de apoyo a Chile con el inicio de la transición, siendo central el rol del PSOE a partir de su llegada al gobierno en 1982, como parte de la política exterior de Felipe González y en defensa de los valores socialistas sobre la realidad internacional. En menor medida está el rol de la Unión de Centro Democrático (UCD), que tuvo mayores dificultades en articular la solidaridad con Chile entre 1977 y 1982, especialmente por la falta de conexiones a nivel internacional, lo que le quitó peso a la promoción de la democratización en Chile y América Latina, pese a su interés en la situación de los derechos humanos. Así, sus mayores grados de cercanía fueron con sectores del PDC, especialmente con los más críticos a la dictadura y al actuar de los sectores conservadores democratacristianos chilenos que apoyaron el golpe de Estado. Por su parte, el PCE planteó su preocupación tanto durante sus años de clandestinidad respecto al tema chileno, acrecentando sus posturas de dar asilo a perseguidos políticos y dar su solidaridad a la oposición chilena como una vez que el partido pasó a la legalidad. Por otra parte, se ha destacado el rol de coordinación y presencia del Comité Sindical Chile, formado por miembros de la disuelta Central Única de Trabajadores (CUT) chilena, de diversidad partidista, que hizo que algunos de sus miembros tuvieran cercanías con las Comisiones Obreras (CCOO) y otros con la Unión General de Trabajadores (UGT)2 ${ }^{2}$. Por el lado de las ONGs, sus posturas estuvieron ligadas a la promoción de los derechos humanos y el trabajo de fundaciones con fines de apoyo a exiliados, especialmente en la gestión de la permanencia de ellos y sus familias en España ${ }^{3}$.

\footnotetext{
${ }^{1}$ Mario Olguín, "Exilio político chileno en España (1973-1990/1994). El caso de Zaragoza. Acercamiento al estudio, avances y discusiones de la investigación", Carlos Forcadell y Carmen Frías (eds), X Congreso de Historia local en Aragón, Zaragoza, Institución Fernando el Católico, 2017, pp. 406-407.

2 Véase Héctor Opazo Romero, Los actores no gubernamentales españoles ante el régimen militar de Augusto Pinochet (1973-1990): Apoyo a la democratización y defensa de los derechos humanos, (tesis doctoral), Madrid, Universidad Complutense de Madrid, 2008, consultado en http://eprints.ucm.es/8798/

${ }^{3}$ Ibid, pp. 6-7.
} 
En este sentido, los estudios se centran en las acciones de exiliados y en la acción de partidos y organizaciones. Sin embargo, no se destaca el caso específico del comunismo catalán, como una de las principales fuerzas comunistas federadas al PCE, respecto al caso chileno, por lo que es central recoger esta arista para comprender las acciones solidarias en el contexto de 1973 a 1980. Por lo mismo, este artículo plantea como hipótesis que las formas de acción del comunismo catalán fueron hegemónicas dentro de la solidaridad con Chile en el periodo estudiado, apoyadas especialmente por el rol opositor durante el franquismo tardío y el peso partidista durante la transición española, especialmente centrado en el papel activo de la juventud comunista catalana hasta el declive de esta, a fines de la década de 1970.

Para abordar teóricamente esta investigación, es necesario establecer conceptualmente la idea de solidaridad política. Para esto, es necesario comprenderla como una serie de acciones que "surge(n) en respuesta a una situación de injusticia y opresión (...) Hay una naturaleza de oposición inherente a la solidaridad política como a una visión mutualmente compartida" 4 , siendo central la historia común de opresión en conjunto a una visión de futuro compartida por diversos grupos y un contenido moral positivo de quienes forman parte de estos movimientos $^{5}$. Así, la solidaridad política se plantea mediante actividades que van en favor de los pueblos oprimidos, con apoyo a proyectos de cambio social, sin una visión unificada respecto a los métodos y objetivos, pero con conciencia colectiva y compartida ${ }^{6}$. Por ende, para el caso chileno, parte de la comunidad internacional apuntó diversamente al objetivo del retorno a la democracia y por el respeto a los derechos humanos. En general, se manifestó en diversas actividades, como actos artísticos y culturales, exposiciones, protestas callejeras, publicaciones, charlas, seminarios hasta la ocupación de espacios representativos del Estado de Chile como forma de crítica a la dictadura.

Del mismo modo, en el contexto del comunismo español, hubo una influencia marcada del eurocomunismo como base de las acciones y la comprensión de la solidaridad. Esta interpretación del comunismo tuvo un doble sentido de comprensión, tanto geográfico como político. En una primera instancia, el desarrollo en el escenario europeo occidental -específicamente en los partidos comunistas de Francia, España y especialmente Italia- se basó en el entendimiento de las complejidades de las sociedades capitalistas del oeste de Europa y en cómo el acceso al poder debía ser mediante una vía pacífica y gradual. Políticamente, implicó el distanciamiento de la ortodoxia soviética del gobierno de Leonid Brézhnev en un contexto de crisis económica y de estancamiento político en la Unión Soviética a inicios de la década de $1970^{7}$, acrecentado por “... la reflexión respecto a sobre el tema de la libertad y del pluralismo y sobre la falta de ellos en los socialismos reales" ${ }^{8}$, fortalecida desde los hechos de la Primavera de Praga de 1968.

En el caso español, las críticas a las posturas soviéticas respondieron a las consecuencias de la represión ortodoxa ante la propuesta reformista checoslovaca y a la influencia de la experiencia chilena de la Unidad Popular 9 , adoptando la vía eurocomunista en 1975 con la Declaración de Livorno en conjunto con el

\footnotetext{
4 Sally J. Scholz, Political Solidarity, University Park, Pennsylvania State University Press, 2008, p. 34, disponible en https://books.google.es/books?id=lV10UTD53E0C\&pg $=$ PT27\&hl=es\&source $=g b s$ toc $r \& c a d=3 \# v=$ onepage\&q\&f $=$ false 5 Ibid, pp. 34-35.

${ }^{6}$ Margaret Power y Julie A. Charpil, "Introduction: On solidarity", Latin American Perspectives 6: 36, Riverside, 2009, p.4, disponible en https://www.jstor.org/stable/20684682

7 Andrea Donofrio, "El final del eurocomunismo y el Partido Comunista de España (PCE)", Studia Histórica - Historia Contemporánea, 31, Salamanca, Ediciones Universidad de Salamanca, 2013, pp. 168-169, consultado en http://revistas.usal.es/index.php/0213-2087/article/view/14597/15051

8 Alessandro Santoni, "Comunistas y socialistas italianos frente a la causa chilena: solidaridad y renovación (1973-1989), Revista www.izquierdas.cl, 19, 2014, p. 113.

9 Ver capítulo 2 de Elías Álvarez Justo, El Eurocomunismo y su influencia en el PCE y el PSUC, (tesis de máster) Barcelona Universidad de Barcelona, 2018, consultado en http://hdl.handle.net/2445/126727
} 
Partido Comunista Italiano ${ }^{10}$. El principal representante de esta postura fue el secretario general del PCE, Santiago Carrillo, que fortaleció su figura desde la legalización comunista de 1977 y la publicación de su libro "Eurocomunismo y Estado". Estas ideas permearon el espacio ligado al PCE, dentro de ellos al PSUC y la JCC, utilizándola como base de sus lineamientos en el contexto transicional catalán, en base a la ruptura política y a la participación electoral gracias a la legalización como organización, lograda durante el gobierno de Adolfo Suárez gracias a los apoyos comunistas italianos y franceses ${ }^{11}$. De esta forma, y bajo este contexto, es necesario comprender el desarrollo de las líneas de acción solidarias con Chile en el periodo 1973 a 1980.

\title{
Internacionalismo proletario y solidaridad de los pueblos como ejes políticos del comunismo catalán
}

En enero de 1978, ante el Comité Central del Partido Comunista de Chile (PCCh) en el exilio, reunido en Budapest, la exsecretaría general de las Juventudes Comunistas de Chile (JJCC), Gladys Marín, se manifestó respecto al rol de la juventud militante comunista en el contexto de las dictaduras latinoamericanas de derechas y el desarrollo de redes internacionales, indicando:

\begin{abstract}
Nuestra juventud, formada desde siempre por nuestro Partido en los principios del internacionalismo, comprende hoy a través de su experiencia más que nunca, el inmenso valor de la solidaridad internacional, y procura, en la medida de sus posibilidades, desarrollar la más alta solidaridad con la lucha de todos los pueblos y juventudes que combaten por su libertad, en primer lugar con nuestros compañeros y todos los demócratas de Uruguay, Brasil, Guatemala, Bolivia, y de demás pueblos de América Latina (...) Hoy en la lucha antifascista el popular grito "Paz, amistad, solidaridad", se hace escuchar en todas las manifestaciones solidarias. ${ }^{12}$
\end{abstract}

El internacionalismo dentro del ideario comunista era uno de los elementos centrales en la coordinación política externa, especialmente en casos de persecución o en el desarrollo de alianzas organizativas para generar redes opositoras. Esta era una política que tanto el PCCh como las JJCC tenían dentro de sus posturas ante la dictadura de Pinochet, dada desde su coordinación en el exilio. Por ejemplo, en 1977 se establecieron encuentros internacionales y juveniles en Italia, coordinados por la dirección de las JJCC con otras juventudes comunistas, creando comisiones con diversos organismos chilenos y extranjeros para generar y fortalecer redes de apoyo en el contexto dictatorial chileno ${ }^{13}$.

Esto no es un tema circunstancial dentro de la política comunista, ya que el sentido de la solidaridad y apoyos más allá de las fronteras nacionales suele estar asociado al ideario internacionalista en su base teórica e histórica. Ya desde los prefacios de Friedrich Engels al Manifiesto Comunista se destacaba el carácter organizativo supranacional de la Liga de los Comunistas y la posterior aparición de la Asociación Internacional de Trabajadores -Primera Internacional-14 como órgano representante del mundo obrero, cuyo sentido e identidad de clase estaba por sobre los intereses nacionales. Esto se acrecentó con las posiciones de la Segunda Internacional que consideró al internacionalismo como la antítesis del

${ }_{10}$ Ibid, p. 9.

11 Ibid, pp. 66-68.

12 Arxiu Nacional de Catalunya (ANC), fondo Partit Socialista Unificat de Catalunya (PSUC), Informe al pleno del Comité Central. Juventudes Comunistas de Chile. Enero de 1978. Rendido por la camarada Gladys Marín, secretaria general de las JJCC. Budapest, Hungría, Partits comunistes i obrers, Budapest, enero de 1978, caja 104, c. 33

13 ANC, fondo PSUC, Informe de la reunión del Coordinador del Exterior de las JJCC de Chile (14, 15 y 16 de enero de 1977), Partits comunistes i obrers, 14-16 de enero de 1977, caja 104, cc. 11-12.

${ }^{14}$ Friedrich Engels, "Prefacio a la edición inglesa de 1888", Karl Marx y Friedrich Engels, Manifiesto del Partido Comunista, Madrid, Fundación de Investigaciones Marxistas, 2013, pp. 29-30, consultado en www.pce.es/descarga/manifiestocomunista.pdf. 
nacionalismo de raíces chovinistas y del dominio estatal que buscaba la integración de las masas en el orden capitalista ${ }^{15}$. Esta matriz se mantuvo durante parte del siglo XX, mediado por el peso hegemónico de la Unión Soviética durante la existencia de la Tercera Internacional y como parte del ideario de los partidos de corte comunista y marxista-leninista. Esta postura fue conocida como internacionalismo proletario, que implicó entender las redes de apoyo comunista bajo el prisma soviético, en un sentido ligado a la obediencia ${ }^{16}$ y de compromiso con partidos comunistas que siguieran la misma línea.

En el caso comunista catalán, el PSUC -principal referente comunista- tuvo una línea acorde al internacionalismo proletario, en especial en la clandestinidad del último periodo de la dictadura franquista ${ }^{17}$. Este partido tuvo un rol de marcada influencia en el tejido opositor de la sociedad catalana, en especial durante la década de 1960 mediante acciones como La Caputxinada ${ }^{18}$, de importancia por ser la primera acción de estudiantes universitarios en torno al Sindicato Democrático de Estudiantes de la Universidad de Barcelona (SDEUB), con fuerte presencia de militantes comunistas y con una crítica al monopolio sindical estudiantil del franquismo. Esta instancia, de gran apoyo ciudadano, fue el origen para el desarrollo de otras organizaciones de la sociedad civil como la Taula Redonda conformada por diversas personalidades del mundo opositor catalán y de la Assemblea de Catalunya, fundada en 1971, central en las formas de acción de la primera mitad de los setenta ${ }^{19}$, dentro del marco de la clandestinidad comunista.

Estas acciones fueron reprimidas duramente por parte de la dictadura de Franco. En especial, desde 1965 a 1975, hubo una acción coordinada por parte de la policía política encabezada por la Brigada Político Social (BPS), principal eje de la represión, persecución y hostigamiento en contra de la oposición democrática, especialmente de izquierda. Esto se reflejó en la muerte del estudiante y militante del Frente de Liberación Popular, Enrique Ruano, tras una serie de protestas estudiantiles en España durante 1969. Este caso fue mostrado como un suicidio del militante antifranquista por parte de la institucionalidad de la época, aunque en la práctica fue asesinado por miembros de la BPS. Además, en esta última etapa, las demandas democráticas, especialmente estudiantiles, tuvieron respuestas mediante el estado de excepción constitucional (de tres meses en 1969) como una forma de frenar las protestas populares y demostrar el control por parte de la dictadura ${ }^{20}$. Otras demostraciones del control franquista en el marco español fueron el Proceso de Burgos contra militantes de ETA en 1970, que impactó diversas expresiones de movilización social en España en apoyo a los acusados. En el caso catalán, además de las restricciones lingüísticas, hubo casos significativos, como la pena de muerte del anarquista Salvador Puig Antich en 1974, siendo el último asesinado en las cárceles catalanas bajo la represión franquista.

En este contexto represivo y de clandestinidad forzada desde 1939, las acciones del PSUC respecto a apoyos solidarios se basaron especialmente en el ámbito de la discusión política interna, dejando el frente público a acciones bajo el alero de organismos amplios como la anteriormente citada Assemblea de Catalunya. Esto se evidenció en el III congreso del partido, realizado en la clandestinidad en febrero de

15 Perry Anderson, "Internacionalismo: un breviario", New Left Review 14, Madrid, 2002, p. 12, consultado en $\underline{\text { http: } / / \text { newleftreview.es/article/download pdf?id=2376\&language }=e s}$

16 Álvarez Justo, op. cit, p. 48.

17 Es necesario clarificar que la clandestinidad del PSUC proviene desde 1939 con la victoria del bando nacional en la Guerra Civil Española. Ver Antoni Lardín i Oliver, "La organización clandestina del PSUC en Cataluña en los años cincuenta", Hispania Nova 5, Madrid, 2005, consultado en http://hispanianova.rediris.es/5/articulos/5a002.htm

18 Josep María Colomer, Els estudiants de Barcelona sota el franquisme. Vol 1, Barcelona, Curial, 1978, pp. 219-229.

19 Antoni Segura i Mas, "Memòria i Història de la transició", en Aracil, Rafael; Segura, Antoni (eds), Memòria de la transició a Espanya i a Catalunya, Barcelona: Edicions Universitat de Barcelona, 2000, pp. 19-20; Carme Molinero y Pere Ysàs, La cuestión catalana. Cataluña en la transición española, Barcelona, Crítica, 2014, p. 143.

${ }^{20}$ Elena Hernández, et. al, Estudiantes contra Franco (1939 - 1975). Oposición política y movilización juvenil, Madrid, La Esfera de los Libros, 2007, p. 264. 
1973, en el que, bajo la idea del internacionalismo proletario, se establecieron políticamente proclamas en apoyo a la causa vietnamita, siguiendo la lógica de la coordinación de los países socialistas y de fuerzas progresistas contra el imperialismo estadounidense ${ }^{21}$. Esta posición del PSUC estuvo en correspondencia con la del PCE en su octavo congreso, respecto a "la lucha por la unidad en la diversidad del movimiento obrero y comunista internacional" 22 . Además, reprocharon el establecimiento de relaciones diplomáticas entre la China comunista y la España franquista, destacando la influencia negativa externa china y el daño a la oposición democrática contra Franco ${ }^{23}$, en pos de una crítica al marxismo maoísta.

A la par del PSUC, la JCC también estableció sus posturas respecto al internacionalismo proletario. Fundada en julio de 1970 en Sabadell ${ }^{24}$ como una organización juvenil de masas, independiente, pero con una política idéntica a la del PCE y del PSUC, y federada a la Unión de Juventudes Comunistas de España (UJCE), se caracterizó por poseer una orgánica construida desde comités locales con tres responsables (político, organizativo y de propaganda), que eran la base de la estructura de los diversos comités mayores en una lógica ascendente (intercomarcal, nacional, ejecutivo) y el congreso de las juventudes ${ }^{25}$. En el plano de las relaciones políticas exteriores, las posturas internacionalistas proletarias estuvieron presentes con un evidente sentido antiimperialistas entre sus militantes: "Nuestros héroes tenían dimensión internacional. Gritábamos eso de 'Ho Chi Min' y ‘yanquis fuera del Vietnam”; había, igualmente salvar a Ángela Davis, una mujer comunista, que querían condenar a cadena perpetua (...) y condenar el aplastamiento de la Primavera de Praga por los tanques soviéticos" 26 . En especial, Chile y la Unidad Popular despertaron simpatías dentro de la JCC, por ser las referencias de Salvador Allende y Pablo Neruda, figuras de importancia ética y política para los jóvenes comunistas catalanes.

Con el golpe de Estado de 1973 contra el gobierno de Allende, la postura de la JCC apuntó a la condena ante el hecho y un llamado abierto a la solidaridad con Chile, especialmente de la juventud, bajo las posturas internacionalistas proletarias y con un discurso de tinte radical y revolucionario, expresando:

La JOVENTUT COMUNISTA DE CATALUNYA se une a la expresión mundial contra el golpe militar fascista, y llama a todos sus militantes y simpatizantes, a toda la juventud combatiente y revolucionaria a tomar en sus manos la defensa del pueblo y de la juventud chilena, A manifestar por todos los medios: pintadas, octavillas, manifestaciones, actos públicos, escritos, conferencias, etc, etc. nuestro apoyo y solidaridad con Chile. Todas las acciones y actividades que se realicen -por pequeñas o insignificantes que nos parezcan- son importantes para impedir nuevos crímenes, mayores matanzas.

En estos momentos, LA TAREA REVOLUCIONARIA MÁS IMPORTANTE, la más urgente, la tarea más inmediata e inaplazable — por encima de cualquier otra consideración - es la LUCHA SOLIDARIA. La más activa y masiva movilización en favor de la juventud y del pueblo chileno. Por su libertad, contra la represión fascista. Distraer nuestra atención principal, en discusiones polémicas o teorizantes, en este momento, sólo favorece a las fuerzas reaccionarias fascistas. El pueblo chileno

21 "Resolució política del III Congrés del P.S.U. de Catalunya", Treball, extraordinario, febrero de 1973, p. 2.

22 "Un congrés de combat", Treball, 28 de febrero de 1973, p. 2

23 “Les relacions Madrid-Pekín. Un 'realisme' que fa tuf', Treball, 14 de marzo de 1973, p. 8.

${ }_{24}$ Carles Santacana (moderador), "Les organitzacions polítiques juvenils" (mesa redonda), Rafael Aracil, Andreu Mayayo y Antoni Segura (eds), Memòria de la transició a Espanya i Catalunya. Els joves de la Transició, vol. IV, Barcelona, Edicions Universitat de Barcelona, 2003, p. 243.

${ }^{25}$ Xavier Domènech Sampere, Temps d’interseccions. La Joventut Comunista de Catalunya (1970-1980), Barcelona, Fundació Francesc Ferrer i Guàrdia, 2008, pp. 87-89.

${ }_{26}$ Domènec Martínez, "Intervencions de diferents protagonistas de la JCC", Fundació Nous Horitzons, 35è aniversari de la constitució del Comitè Nacional de la Joventut Comunista de Catalunya, Barcelona, Fundació Nous Horitzons, 2005, p. 14, consultado en http://www.noushoritzons.cat/ca/ file/156002/download?token=ybzhoMgD 
reclama, necesita angustiosamente, solidaridad con su heroica lucha de resistencia. Este es nuestro - primer deber revolucionario internacionalista hoy (...)

Los jóvenes comunistas de Catalunya intensificaremos nuestro esfuerzo solidario, incrementando la lucha por la liquidación de la dictadura en nuestro país. Por hacer 'triunfar la causa liberadora de los hombres' por la victoria del Socialismo y el Comunismo.

"SE SIENTE, SE SIENTE, ALLENDE ESTÁ PRESENTE"

El C.E. DE LA JOVENTUT COMUNISTA DE CATALUNYA 20 setembre $1.973^{27}$

Además, en una línea similar a la del PSUC en su III congreso respecto al internacionalismo, destacaron sobre Chile que "Si el internacionalismo proletario es una necesidad constante en nuestra lucha cotidiana, su significado adquiere hoy hacia CHILE un llamamiento apremiante, se convierte EN UN DEBER SAGRADO DE TODO REVOLUCIONARIO"28, en una crítica abierta a la situación chilena, al intervencionismo de Estados Unidos como expresión imperialista y en un llamado directo a toda la juventud para formar un movimiento amplio de solidaridad con Chile. En este sentido, igualmente se marcó una diferencia entre el aparato juvenil y el central, siendo el primero de un carácter más público para manifestar apoyos clandestinos, a diferencia del rol político interno de la segunda organización. Esto, en concordancia con destacar este tipo de acciones en otros países, como las primeras intervenciones de otras juventudes políticas, como la ocupación de la embajada de Chile en París en pos de la liberación del secretario general del PCCh, Luis Corvalán, efectuado por las juventudes comunistas francesas ${ }^{29}$. Si bien este tipo de manifestaciones eran imposibles bajo el ámbito represor del franquismo, eran parte de un sentido internacionalista, radical y revolucionario en lo discursivo ante la situación chilena.

\section{El cambio del internacionalismo proletario a la solidaridad entre los pueblos: la influencia eurocomunista.}

Tras la muerte de Franco en 1975, el PSUC comenzó un viraje en la revisión de sus posturas. Para 1976, todavía en la clandestinidad, plantearon un nuevo concepto: la solidaridad dentro del internacionalismo, pero dejando de lado el concepto proletario en su acción. Esto, en función de la influencia del eurocomunismo y la lejanía de las posturas soviéticas ${ }^{30}$ en el seno del PCE y del mismo PSUC. Así, ejemplificando desde el caso chileno, el comunismo catalán destacó la importancia de la defensa constante de la lucha por la paz y la coexistencia pacífica "sin la cual la revolución dejaría de ser un hecho nacional y la lucha de clases en cada país ya no sería el motor de una historia abocada a la barbarie y la destrucción" 31 , estableciendo una crítica al camino previo de las relaciones internacionales.

Esta nueva postura se consolidó en el IV congreso del PSUC realizado en octubre de 1977, marcando las diferencias con las posturas del congreso de 1973. En esta instancia, la primera en la legalidad alcanzada en mayo del mismo año, se remarcó la idea de la solidaridad "con todos los pueblos" por sobre el internacionalismo proletario ${ }^{32}$. No solamente fue la crítica al imperialismo estadounidense, sino también al rol soviético como bloque hegemónico mediante sus diversas intervenciones. En concordancia con esta postura, Antoni Gutiérrez, nuevo secretario general del PSUC, destacó en su primer discurso ante el pleno del congreso la importancia de la solidaridad con otros países, que "por el hecho de serlo, exige el

\footnotetext{
27 "Solidaridad con Chile", Jove Guàrdia, agosto-septiembre 1973, p. 11. Mayúsculas y subrayados son de la fuente.

28 "Chile bajo el terror nazi", Jove Guàrdia, 15 de enero de 1974, p. 8. Mayúsculas son de la fuente.

${ }^{29}$ Idem.

30 Álvarez Justo, op. cit. p. 85.

31 "Una revolució universal", Treball, extra, julio de 1976, p.7.

32 "El PSUC acabà el IV Congrés", Avui, 2 de noviembre de 1977, p. 5.
} 
respeto a la independencia hacia los planteamientos específicos de las fuerzas revolucionarias de todos los países. Sin injerencias, sin pretensiones hegemónicas"33. La postura del PSUC quedaba establecida: solidaridad con los pueblos, respeto a la autodeterminación, evitar un intervencionismo de tipo hegemónico y la superación del internacionalismo proletario. Era entender el apoyo con los países en lucha por su libertad, "contra el fascismo, las dictaduras y el imperialismo que hoy los oprimen, como es en Chile, Argentina, Uruguay y Brasil en América Latina..."34. Por lo tanto, existió una postura clara en considerar este elemento como central en la comprensión del proyecto político comunista, dentro de los márgenes de la solidaridad entre los pueblos.

Posteriormente, el mundo juvenil comunista catalán se reunió en el I congreso de la JCC efectuado el 11 de noviembre de 1977 en el Palacio de Congresos de Montjuïc de Barcelona

se discutieron temas internos, el rol de los movimientos juveniles y sobre las tensiones de la transición política española entre las posturas sobre la ruptura con el franquismo en contra de la reforma política ${ }^{35}$. Además, en este mismo espacio, con presencia de delegados invitados de las JJCC de Chile ${ }^{36}$, se establecieron posturas de apoyo a los pueblos oprimidos, no desde las consignas abiertamente revolucionarias de 1973, sino desde una óptica solidaria, delimitada en el informe del congreso de la siguiente manera:

Hasta hace unos meses nuestro internacionalismo se reflejaba en la necesidad de solidaridad de las organizaciones juveniles y del conjunto de los países democráticos y progresistas con la lucha antifascista del pueblo español. Esta ayuda ha sido importantísima y sin duda, sin esta solidaridad difícilmente hubiéramos ganado la batalla.

Ahora las cosas han cambiado. En estos momentos estamos en una situación más favorable para expresar nuestra solidaridad efectiva con el resto de los pueblos del mundo.

Como JCC hemos planteado nuestra política en este sentido a varios niveles:

1) Participar activamente en la política internacional de la UJCE.

2) "Hermanarnos" con organizaciones juveniles comunistas de los países con más proximidad política y geográfica. Así, con la FGCI (del Piamonte), MJCF (región de Marsella), J.C de Grecia, del Interior (región de Salónica), y hemos tenido conversaciones con las Juventudes Comunistas de Yugoslavia.

3) Incidir directamente en las acciones que hoy son preocupación de la juventud europea (el paro juvenil, cuestiones ligadas al eurocomunismo).

4) La solidaridad activa con el Frente Polisario y la lucha antifascista de los pueblos latinoamericanos y especialmente Chile.

Esta solidaridad no se expresa, simplemente con la actividad del CE en este sentido, sino, que fundamentalmente debe ser descentralizado, de realizar múltiples actividades a nivel de cada colectivo y de localidad (creación de comités unitarios de ayuda, campañas de sensibilización, a través de festivales, charlas, (...). Por ello es preciso que exista esta preocupación constante en cada colectivo para multiplicar estas actividades. $^{37}$

De esta forma, los nuevos lineamientos estuvieron marcados por la solidaridad y en mecanismos de acción en los cuales poder incidir, dado el fin de la dictadura franquista y el proceso de transición en España. Además, se destacó que las relaciones internacionales poseían diversas esferas. Una de ellas

33 “Quatre 'sí', quatre 'no', quatre 'visca”', Treball, 29 de octubre al 4 de noviembre de 1977, p. 7.

34 Idem.

35 Domènech Sampere, op. cit., p. 162.

36 "Un congrés d'alternatives: cap al socialisme per viure lliure", Treball, 18 de noviembre de 1977, p. 8.

${ }^{37}$ Joventut Comunista de Catalunya, I Congrés: Informe general, Barcelona, JCC, 1977, pp. 31-32. 
responde a lo nacional y la relación con la Unión de Juventudes Comunistas de España (UJCE). La siguiente es europea, pero centrado en las relaciones con juventudes comunistas de países occidentales o que no eran parte del Pacto de Varsovia (Yugoslavia), en una línea lejana de las relaciones con el mundo soviético, lo que también se hace patente en plantear el eurocomunismo como un eje de discusión juvenil. La última, cercana al tercer mundo, destaca tanto al Frente Polisario en el Sahara Occidental como el caso chileno, en una postura de apoyo a sus causas.

En la misma línea, la resolución política general de cierre del I congreso apuntó a la solidaridad y destacó especialmente a Chile, indicando:

El I Congreso ha reafirmado los principios de paz, libertad y amistad entre los jóvenes de todo el mundo, y la solidaridad antifascista y antiimperialista con los jóvenes y los pueblos que padecen opresión alrededor del mundo.

El I Congreso se compromete a la solidaridad activa con la lucha antiimperialista de los pueblos latinoamericanos, concretamente en Chile y exige al gobierno español el voto condenatorio del régimen de Pinochet en la próxima sesión plenaria de la ONU. 38

Así, la solidaridad se entiende en función de diversas actividades de cooperación, del rechazo a la intervención imperialista externa y a la crítica contra el fascismo, en línea con lo planteado en el IV congreso del PSUC, relevando la solidaridad entre los pueblos por sobre el internacionalismo proletario y la posibilidad de intervenciones de terceros actores que influyesen en las decisiones de los países. De este modo, la consecución de una línea común no se debe sólo a una direccionalidad u obediencia de la JCC respecto al PSUC 39 , sino a la sintonía crítica de ambas organizaciones ante las situaciones que afecten derechos y libertades. Así se manifestó la postura de apoyar en los espacios correspondientes y con mecanismos delimitados, pero manteniendo como base el criterio de la autodeterminación de los pueblos. La retórica internacionalista de acción directa y revolucionaria de 1973 -en el III congreso del PSUC y en las declaraciones de la JCC contra el golpe de Estado en Chile- dieron paso a esta nueva forma de comprender las relaciones solidarias entre países, y las formas de acción correspondientes, cercanas al eurocomunismo y contrarias al internacionalismo proletario.

\section{Cooperación desde el comunismo juvenil catalán}

Las primeras actividades a favor de Chile impulsadas desde la JCC se manifestaron, concretamente, a partir de 1976. Los días 10 y 11 de octubre de ese año se llevó a cabo clandestinamente la IV Conferencia de la UJCE, en un seminario eclesiástico en Sentmenat, a las afueras de Barcelona. Las conclusiones de esta conferencia fueron públicas, con acceso a la prensa, efectuada en la Iglesia de la Virgen de Montserrat en el barrio de Guinardó ${ }^{40}$. En este plenario abierto de clausura estuvieron presentes, además de los delegados de las diversas juventudes comunistas, representantes de orgánicas juveniles extranjeras ${ }^{41}$, como miembros de la Federación Mundial de la Juventud Democrática (FMJD), de las juventudes comunistas griegas, francesas, belgas e italianas, además del Frente Polisario ${ }^{42}$, siendo uno de los

\footnotetext{
38 "El moviment juvenil de la libertat", Treball, 11 al 18 de noviembre de 1977, p. 9.

${ }_{39}$ De hecho, los estatutos del IV congreso del PSUC destacaban la independencia de la JCC respecto al Partido, en una relación basada en la fraternidad y los apoyos necesarios para fortalecer la orgánica juvenil. Véase Partit Socialista Unificat de Catalunya, Estatutos del Partit Socialista Unificat de Catalunya. IV congreso (1977), Barcelona, PSUC, 1977, p. 13, consultado en http://biblioteca.andalucia.ccoo.es:8080/intranet-tmpl/prog/local repository/documents/14948 6696.pdf.

40 Santacana, op. cit., p. 251.

41 "Se clausuró el IV Congreso de la Unión de Juventudes Comunistas de España”, La Vanguardia Española, 14 de octubre de 1976, p. 29.

42 Santacana, op. cit., p. 253.
} 
expositores el militante de las JJCC, Antonio Fernández. Al cierre de la exposición del último, el grito mayoritario fue "el pueblo unido jamás será vencido" 43 , proclama proveniente de la misma canción interpretada por el grupo chileno Quilapayún, en favor de las palabras de Fernández sobre la situación en Chile.

De esta manera, se efectuó un doble reconocimiento a la causa chilena. En primer orden, la visibilizó en la discusión política de las juventudes comunistas españolas y catalana, dada la capacidad organizativa de la JCC. Por otro lado, la conferencia pública implicó clarificar el apoyo con la juventud chilena, mediante las JJCC, apoyando la lucha por la democracia, pero dentro del margen institucionalizado de una reunión de tipo política.

Desde 1977, las expresiones de solidaridad se masificaron de manera más clara, a nivel de la juventud comunista, del PSUC y otros partidos de izquierda. Esto se vio influido, en parte, por la legalización del PSUC y de la JCC en mayo de 197744 , lo que dio un mayor margen de acción fuera de los espacios de clandestinidad en que estuvieron como consecuencia del franquismo. Esto permitió el 13 de mayo de 1977 efectuar un gran acto encabezado por el poeta español Rafael Alberti en la Plaza Las Arenas, en homenaje a Pablo Neruda, y en solidaridad con Chile y los pueblos de América Latina en dictadura, como lo señaló el político y candidato al Senado español, Josep Benet en su intervención:

Venimos a promover la solidaridad de todos los pueblos del estado español con los pueblos que sufren la represión y la dictadura en América Latina... Venimos a recabar la solidaridad con los compañeros de Chile, de Argentina, de todo el continente latinoamericano, que están aquí, entre nosotros, exiliados. Venimos para evocar a Pablo Neruda, el hombre que estuvo a nuestro lado en aquellos días amargos de aquella guerra nuestra... ${ }^{45}$

En este acto, además, estuvieron presente diversos artistas chilenos en el exilio, como Inti-Illimani, la Brigada Pablo Neruda (pintura muralista) junto a cantantes catalanes como Joan Isaac y Quico Pi de la Serra ${ }^{46}$. Este espacio, dirigido por Alberti, fue una oportunidad para mostrar la solidaridad a nivel artístico-cultural y político en favor de la democracia chilena y en denuncia de la dictadura de Pinochet.

Este fue el inicio de la llegada masiva a Barcelona de actividades culturales ligadas al comunismo chileno. Por ejemplo, después de su primera visita en 1974, Quilapayún actuó en el Palau Blaugrana de la capital catalana ${ }^{47}$, destacando su presentación tanto a nivel artístico como por su motivación política, lo que era esperado por la prensa. Según lo consignado en Avui "con sus canciones llegará la voz del pueblo chileno, un pueblo que protagoniza una de las experiencias más esperanzadoras de libertad, y que actualmente vive sometida a una dictadura asesina, y que pese a esto continúa con la esperanza expresada en las canciones" 48 .

El carácter político de esta presentación, por el contenido y las proclamas en apoyo a la situación chilena, tuvo un impacto en los sectores juveniles comunistas catalanes. La JCC contactó al grupo chileno y firmó

43 "IV Conferència de la UJCE a Barcelona. Cap als 100.000 militants", Treball, 18 de octubre de 1976, p. 8.

44 "Legalizado el Partido Socialista Unificado de Cataluña (PSUC)", El País, 4 de mayo de 1977, consultado en https://elpais.com/diario/1977/05/04/espana/231544808 850215.html; Arxiu Biblioteca Pavelló de la República de la Universitat de Barcelona (ABPR), “Avanza la democracia. Un primer balance de la campaña electoral”, Jovent, verano 1977, p. 6, carpeta pp-14.

45 "Recuerdo a Neruda, presencia de Alberti", La Vanguardia Española, 15 de mayo de 1977, p. 23.

46 "Alberti, a Barcelona", Treball, 16 al 22 de mayo de 1977, p. 8.

47 Andreu Mayayo i Artal, , La ruptura catalana, Barcelona, Editorial Afers, 2002, p. 31.

48 "Quilapayún: la veu del poble xilè", Avui, 23 de marzo de 1977, p. 25. 
un contrato el 24 de junio de $1977^{49}$ para la presentación en la Gran Festa de Jovent a realizarse el 2 de julio del mismo año, en compañía de artistas locales como María del Mar Bonet, Quico Pi de la Serra, entre otros, además de dirigentes del PSUC y el secretario general de la JCC ${ }^{50}$. Finalmente, la fiesta se desarrolló con la asistencia de 15.000 personas, la presencia de la cúpula del PSUC, la JCC y de Santiago Carrillo, secretario general del PCE. En lo artístico, en el momento de la presentación de Quilapayún, las críticas al régimen de Pinochet por parte del público, se entrecruzaron con canciones como "Venceremos" y "El pueblo unido jamás será vencido" 51 , como parte de las proclamas centrales de vinculación con Chile en este evento político y cultural.

Otras actividades por parte de la JCC se desarrollaron en campañas de apoyo a la causa chilena, especialmente en cercanías a la conmemoración del 11 de septiembre. En 1977, las juventudes comunistas italianas presentaron el documento "Por la vida y la libertad en Chile", cuyo fin era condenar la situación en Chile mediante la entrega de este escrito al secretario general de las Naciones Unidas, Kurt Waldheim. Se hizo una campaña de recolección de firmas por 46 países, y en Cataluña la JCC estuvo a cargo de esta actividad durante agosto y septiembre, resaltando la relación con Chile sobre el 11 de septiembre, de importancia tanto para Cataluña por la Diada 52 como por el golpe de Estado de 1973 en Chile, estableciendo esta jornada como un llamado a la solidaridad, especialmente a la juventud catalana con la causa chilena ${ }^{53}$. Esto se relacionó con la coordinación, por parte de la agrupación del PSUC del barrio de Plaza Cataluña, de una actividad a favor de la oposición chilena y los pueblos sudamericanos en dictaduras, ofrecido como una celebración de tipo unitaria, pero que finalmente quedó como una actividad exclusiva de los comunistas bajo el argumento de no ser parte de la catalanidad de la Diada y con restricciones horarias para no interferir con las actividades nacionales de ese día ${ }^{54}$.

Pese a estas acciones de carácter unitario entre la JCC y el PSUC, también se vivieron episodios de descoordinación entre ambas organizaciones. Esto se manifestó en la segunda Festa de Treball de septiembre de 1977. Dentro de la planificación de esta actividad, la JCC fue parte de la programación y coordinación, que contó con presencia chilena del grupo Inti-Illimani y de muralistas chilenos ${ }^{55}$, contactados por la JCC. Sin embargo, durante el desarrollo de la Festa hubo problemas con el stand que el PSUC facilitó a la JCC, quedando fuera del recinto de Montjuïc, en una zona de poco tránsito de personas, sin actos o actividades de importancia. La situación solamente se superó mediante el desarrollo de un mitin improvisado y sin soporte técnico por parte de Antonio Leal, militante de las Juventudes Comunistas de Chile ${ }^{56}$ exiliado en Italia, quien en su discurso expresó

Compañeros catalanes: Esta manifestación, este mitin improvisado, pero lleno de calor humano que aquí realizamos, en esta Festa de Treball del PSUC, como los que se han venido realizando en toda España para repudiar al fascismo de Pinochet,

\footnotetext{
49 ANC, fondo PSUC, Engagement entre la JCC et Les Quilapayún, Joventut Comunista de Catalunya (JCC). Actes, festes y homenatges, París, 24 de junio de 1977, caja 79, cc. 1-4.

50 "Convocatoria de actos políticos", La Vanguardia Española, p.7.

51 "Visca, visca, visca, Joventut Comunista", Treball, 3 al 10 de julio de 1977, p. 9.

52 La Diada es el Día Nacional de Cataluña, en el cual se conmemora el fin de la resistencia de Barcelona ante las tropas borbónicas el 11 de septiembre de 1714, en el contexto de la Guerra de Sucesión Española que enfrentó a Borbones y Habsburgos por el trono hispano. Realzado como día nacional desde fines del siglo XIX, es una jornada simbólica en la representación de la identidad catalana. Para más, ver Pere Anguera, "El 11 de septiembre. Orígenes y consolidación de la Diada", Ayer, 51, Madrid, 2003, pp. 17-38, consultado en http://revistaayer.com/sites/default/files/articulos/51-1-ayer51 DiasEspana Anguera.pdf

53 "Recogida de firmas en protesta por situación en Chile", La Vanguardia Española, 27 de agosto de 1977, p. 9.

54 "La Diada, arreu de Catalunya", Avri, 24 de agosto de 1977, p. 5.

55 ANC, fondo PSUC, Proyecto para la Festa del Treball a realizarse el 17 y 18 de septiembre, Joventut Comunista de Catalunya (JCC). Comitè Executiu, 8 de julio de 1977, caja 77, c. 24.

56 ANC, fondo PSUC, Algunas consideraciones sobre la "2 festa del treball" y la participación de la Joventut Comunista de Catalunya, Comitè Executiu, s.f. (1977), caja 76, c. 1.
} 
demuestran sobre todo una cosa, que la represión más feroz, ique los crímenes más atroces del fascismo no pueden destruir a los comunistas ni a las ansias de libertad de los pueblos! ${ }^{17}$

La JCC levantó una crítica ante esta situación, por la poca visibilidad de la juventud en la principal fiesta del comunismo catalán a nivel interno. A pesar de esto, en lo público se destacaron las palabras de Leal mediante una entrevista en la revista oficial de la JCC: Jovent. En este espacio, el dirigente chileno, además de destacar la situación política en Chile para 1977, destacó los apoyos brindados por las juventudes comunistas catalanas y españolas, así como otras expresiones juveniles demócratas y progresistas, destacando los nexos entre España y Chile mediante una paráfrasis a Neruda: "Tan amigo de España es para nosotros el pan y el agua, que nos permite desarrollar el combate por la liberación de Chile" 58 . En la práctica, fue dar un espacio que no se desarrolló de manera clara durante el acto de la Festa del Treball para expresar de mejor forma la situación chilena.

En noviembre de 1977 se llevó a cabo el I congreso de la JCC con presencia de militantes comunistas chilenos, además de palabras de reconocimiento contra la dictadura de Pinochet. En este cónclave, además de las posturas planteadas por la JCC respecto a la solidaridad entre los pueblos, se generaron espacios a que algunos delegados dieran proclamas explicando la situación de sus países. La revista Jovent destacó:

Los aplausos solidarios a Carmina Martínez [delegada uruguaya] se juntaron de inmediato con el 'Chile, Chile, Chile, solidaridad' que cubrieron las primeras palabras de Claudio Reyes, representante de las Juventudes de la Unidad Popular. En su intervención, demandó que el gobierno español vote favorablemente a la condena contra el régimen de Pinochet, que se presentará en la próxima asamblea de la ONU. “Camaradas, con su apoyo se abrirán las amplias alamedas por donde pasará el hombre libre para construir una sociedad mejor"59

De esta forma, entre las posturas del pleno y las palabras del militante chileno, lo planteado durante el congreso estuvo marcado por un carácter discursivo y de resoluciones políticas, siendo el inicio de una mayor coordinación en el ámbito de las relaciones internacionales por parte de la JCC. En el balance posterior, hecho por el Consejo Ejecutivo, respecto a las tareas a desarrollar por el Consejo Nacional, se destacó la importancia de regularizar las tareas de redes extranjeras de la JCC, específicamente en eventos como el Festival de Cuba, el Comité de Solidaridad con Chile ${ }^{60}$ y el X aniversario de la Primavera de Praga ${ }^{61}$. Por lo tanto, era necesario dar un paso en la práctica de los mecanismos de acción en el espacio de congresos y conferencias como en otras dimensiones políticas y públicas.

57 ABPR, “Chile vencerá!”, Jovent, octubre de 1977, p. 11, carpeta pp-14.

58 Ibid, p. 13.

59 ABPR, "Sessió d'obertura", Jovent, enero-febrero de 1978, p. 15, carpeta pp-14. Negritas son de la fuente.

60 Creado en Madrid en 1976 por intelectuales y políticos comunistas y socialistas, cuya finalidad fue "adoptar y encauzar las iniciativas que se orienten a la denuncia de los derechos que revelan la real identidad del régimen imperante en Chile, y las que tienden a prestar ayuda y asistencia a los demócratas chilenos perseguidos". En junio de 1978 se estableció el Comité Catalán de Solidaridad con Chile, en apoyo a una huelga de hambre efectuada en Chile y que tuvo su réplica en la Iglesia de Santa Cecilia en Barcelona. El objetivo de este comité fue "Informar y denunciar ante la opinión catalana la dramática situación que vive el pueblo chileno bajo la dictadura de Pinochet". En "Se constituye el Comité español de solidaridad con el pueblo chileno", La Vanguardia Española, 13 de octubre de 1976, p.4; "Comité catalán de solidaridad con los presos chilenos", La Vanguardia, 8 de junio de 1978, p. 28; “Xile, a prop”, Treball, 9 al 15 de junio de 1978, p. 2.

61 ANC, fondo PSUC, Después de nuestro I Congreso, Joventut Comunista de Catalunya (JCC), Comitè Executiu, declaracions i resolucions, 1970-1979, s.f (1977), caja 76, c.9. 
Así, durante 1978 el comunismo juvenil catalán mantuvo sus acciones de apoyo a la causa chilena, dado el quinto aniversario del golpe de Estado, lo que marcó un sentido de auge en las actividades solidarias en el espacio catalán. A nivel cultural, se presentaron durante ese año representantes de la Nueva Canción Chilena ligada a la izquierda, como Inti-Illimani, que se presentó el 27 de enero en el Palau Municipal $d^{\prime} E s p o r t s$ de Barcelona ${ }^{62}$. El 21 de mayo, en la Festa del Baix del PSUC se presentó la cantautora Tita Parra, con un fuerte apoyo del público con Chile ${ }^{63}$. Posteriormente, el 25 de mayo se efectuó el recital de Ángel Parra y Ayacucho en el Palau d'Esports de Montjüc, organizado por exiliados chilenos adherentes a la Unidad Popular, que tuvo como consigna la solidaridad con los niños chilenos, mediante la petición de materiales escolares de aporte ${ }^{64}$ y que tuvo la presencia de senadores de la Entesa dels Catalans como Josep Benet y Lluis María Xirinacs.

En este contexto, de fuerte presencia cultural chilena, el 16 de julio del mismo año se desarrolló la II Festa del Jovent en el parque de Montjuïc. En ésta se llevaron a cabo una serie de charlas y actividades relacionadas con el tema chileno, en conjunto con el caso argentino, uruguayo y del Frente Polisario en el Sahara, dentro de la llamada "ciudad internacional" enclavada en la zona del Pueblo Español del Montjuï ${ }^{65}$. En el cierre de la fiesta se le dio la palabra a un representante de los Montoneros argentinos para que resumiera la situación en su país ${ }^{66}$. Mientras, en la Festa del Treball del PSUC, del mismo año, la presencia de actos cooperativos con Chile se manifestó con la presencia de miembros del PCCh en un stand propio en la zona del Palau de Victòria Eugènia, junto a otras representaciones comunistas, además de la presencia de la Brigada Muralista Pablo Neruda quien diseñó un mural como parte de la decoración del recinto de Montjuïc ${ }^{67}$. Sin embargo, no se destacaron actividades de la JCC sobre Chile u otras demandas hacía países en dictaduras en la prensa oficial del PSUC ni en otras instancias informativas o documentales.

Pese de no ser evidenciada en la Festa del Treball, la JCC manifestó nuevamente sus apoyos solidarios con Chile y la oposición a las dictaduras durante su IV conferencia política efectuada del 20 al 22 de octubre. En esta instancia nuevamente se reiteró la presencia de invitados chilenos y uruguayos, destacando la lucha unitaria

por acabar con el fascismo en América Latina. Todavía suenan entre nosotros los cantos de Quilapayún hechos hace pocos días aquí y que todos juntos, ellos y nosotros, jóvenes en su inmensa mayoría, nos unimos con el grito de ¡Chile, Chile, Chile y solidaridad! (...) Al dirigirles la bienvenida a todos ustedes no lo hemos hecho por formalismo. Queremos expresar que para las JCC la solidaridad entre todos los jóvenes del mundo, la solidaridad y la ayuda con todos los jóvenes que padecen la opresión sea del tipo que sea, el reforzamiento de la amistad y de los intercambios de todo tipo son para nosotros, para los jóvenes comunistas, tareas prioritarias y fundamentales ${ }^{68}$

\footnotetext{
62 "Espectacles", Treball, 20 al 26 de enero de 1978, p.14.

63 "La festa del Baix", Treball, 19 al 25 de mayo de 1978, p. 11.

64 Treball, 19 al 25 de mayo de 1978, p. 10.

65 ANC, fondo PSUC, Organitració de l'acte central de la Feste del Jovent, Joventut Comunista de Catalunya (JCC), Actes, festes i homenatges 1978, s.f. (1978), caja 79, c.1; ANC, fondo PSUC, Comitè executiu de la JCC, Joventut Comunista de Catalunya (JCC), Actes, festes i homenatges 1978, 14 de junio de 1978, caja 79, c.1.

66 "La festa de 'Jovent", Treball, 21 al 27 de julio de 1978, p. 12.

67 "Una gan festa per a tothom", Treball, 14 al 20 de septiembre de 1978, p. 13.

68 ANC, fondo PSUC, Un projecte revolucionari per a la joventut de Catalunya: Informe del comitè executiu (20, 21 i 22 d'octubre de 1978), Joventut Comunista de Catalunya (JCC), IV Conferència Nacional, 22 de octubre de 1978, caja 76, c.1
} 
De esta forma, nuevamente dentro de las instancias políticas de la JCC se presentaba el tema de la solidaridad con los pueblos como premisa, en función de las relaciones entre las juventudes como elemento central. Esto se une a las propuestas de fortalecimiento de lazos que surgieron posterior al I congreso, manteniendo la línea política respecto a la cooperación en las relaciones internacionales entre juventudes comunistas.

En el mismo contexto de apoyos a Chile, pero a un nivel nacional, el hito más importante durante 1978 fue la Conferencia Mundial de la Solidaridad con Chile realizada en Madrid entre los días 8 y 12 de noviembre. Este encuentro, como primera demostración de fuerzas coordinadas entre chilenos y españoles demócratas, fue organizado por las fuerzas políticas chilenas en el exilio (socialistas, comunistas y radicales) en conjunto con la organización católica Justicia y Paz, además de organizaciones y políticos internacionales como el primer ministro finlandés, Kalevi Sorsa, el senador estadounidense Edward Kennedy y los secretarios generales de los partidos comunista, socialista, socialdemócrata y demócrata cristiano de Italia ${ }^{69}$. También se plegaron las minorías del parlamento español -socialistas, comunistas (PCE, PSUC), socialistas del Congreso, Minoría Catalana y Minoría Vasca-, quienes indicaron que "las minorías parlamentarias acá firmantes harán cuanto esté a su alcance para corresponder a la ayuda recibida del pueblo de Chile en nuestra propia lucha por la libertad y para que los derechos humanos sean respetados en todo el mundo" 70 . Inicialmente la UCD también iba a participar en esta conferencia, aunque finalmente se restó de la actividad, criticando la ausencia de miembros de la Democracia Cristiana chilena y la influencia soviética en este encuentro, aunque explicitando la preocupación por la situación democrática en Chile ${ }^{71}$. Finalmente, el cierre del encuentro derivó en el Acta de Madrid, que destacó la solidaridad con Chile y la unidad de todos los países en función de la libertad y el derecho a elegir, asumiendo la conferencia el deber del compromiso para impulsar las iniciativas acordadas ${ }^{72}$.

A nivel juvenil se realizó el Foro Mundial de la Juventud y los Estudiantes en Solidaridad con Chile -10 de noviembre de 1978- de manera paralela a la Conferencia Mundial de la Solidaridad con Chile, "organizado conjuntamente (por) la Federación de Juventudes Socialistas de España, Unión de Juventudes Comunistas de España, Juventudes Unidas de Centro Democrático y la Unidad Popular Juvenil Chilena en España"73. Este encuentro se desarrolló en el Hotel Convención, sede central de la Conferencia Mundial de la Juventud ${ }^{74}$. La JCC, durante su IV conferencia se adhirió a este encuentro, manifestando que:

Con esta adhesión queremos poner de manifiesto una vez más nuestra decidida voluntad solidaria para con los jóvenes chilenos que se encuentran en la lucha contra la dictadura fascista del general Pinochet.

La JCC trabajará en la medida de sus posibilidades para conseguir una movilización masiva de la juventud de Catalunya en torno al Foro Mundial, exigiendo explicaciones sobre los jóvenes chilenos desaparecidos, y mostrando nuestro apoyo al movimiento estudiantil y de jóvenes trabajadores que se está forjando en el interior de Chile.

69 "Madrid, sede de la Conferencia Mundial de Solidaridad con Chile", El País, 20 de julio de 1978, consultado en https://elpais.com/diario/1978/07/20/internacional/269733605 850215.html

70 "Las minorías del Congreso apoyan la conferencia sobre Chile", La Vanguardia, 3 de noviembre de 1978, p. 7.

71 "Editorial: Solidaridad con Chile", El País, 12 de noviembre de 1978, consultado en https://elpais.com/diario/1978/11/12/opinion/279673202 850215.html.

72 ABPR, "Éxito de la conferencia de solidaridad con Chile", Automnibus, inperiòdic de Barcelona de la Joventut Comunista de Catalunya, s.f (1978), p. 5, carpeta 1/4-6.

73 Arxiu Històric de Comisiones Obreras de Catalunya (AHCO-C), “Que cal fer solidaritat amb Xile”, El butlleti de la JCC. Òrgan d'ús intern de la Joventut Comunista de Catalunya, primera semana de noviembre de 1978, p. 7, consultado en http://biblioteca.ccoo.cat/intranet-tmpl/prog/en/local repository/documents/17822 39428.pdf

74 "Madrid: Prosigue la Conferencia Mundial sobre Chile", La Vanguardia, 11 de noviembre de 1978, p. 8. 
La JCC estamos convencidos de que este importante evento va a contribuir en gran medida a dar un nuevo impulso al movimiento solidario con Chile en todo el mundo, y por ello, vamos a poner todos nuestros esfuerzos para su buena organización y desarrollo ${ }^{75}$

De esta manera, la JCC estableció una coordinación mediante su comité de relaciones internacionales para preparar esta conferencia, centrándose en tres elementos: "la difusión del Foro Mundial de la Juventud, adhesiones y saludos (organizaciones juveniles, personalidades, entidades, etc.) у ayuda económica" "76. La JCC desarrolló una rápida organización -debido al corto tiempo- para apoyar la difusión mediante charlas, presentaciones, saludos por la prensa, pasacalles, fiestas y otros, además de la recolección de fondos en apoyo a la asistencia y funcionamiento del Foro, desarrollando posteriormente un balance de la Conferencia y el foro, destacando los debates con el movimiento estudiantil universitario chileno y otros temas juveniles ${ }^{77}$.

Finalmente, la JCC destacó la importancia de la solidaridad con Chile mediante la Conferencia y el Foro, ya que estas instancias:

\begin{abstract}
han de llevarse a cabo e impulsarse por todos los demócratas y antifascistas del mundo. Más aún, esta expresión solidaria ha de materializarse en la XXXIII Asamblea de la Naciones Unidas a realizarse en diciembre próximo, que debe condenar nuevamente las violaciones de los Derechos Humanos que comete Pinochet y exigir el esclarecimiento por parte de la Comisión Investigadora de los crímenes de la Junta, los casos de los prisioneros políticos desaparecidos. Esta condena de la Asamblea de la NU, así como también la Conferencia, es un nuevo golpe asestado contra el fascismo imperante en Chile y en el cono sur de América Latina ${ }^{78}$
\end{abstract}

Pese a este llamado de condena, durante 1979 el impulso desde el comunismo juvenil catalán hacia la causa chilena bajó en intensidad y acciones. En general, lo realizado durante este año estuvo bajo el alero del PSUC, con poca presencia de la JCC. Así, entre 1979 y 1980, el PSUC estableció líneas trabajo en apoyar causas en sintonía con orgánicas políticas del mundo sindical. Por ejemplo, en septiembre de 1979 se desarrolló la semana del boicot mundial contra Chile impulsada por la multisindical chilena Central Única de Trabajadores (CUT) en el exilio en conjunto con la UGT y CCOO en España ${ }^{79}$, ante la que el PSUC hizo un llamado a plegarse a esta protesta en solidaridad con los trabajadores chilenos ${ }^{80}$.

Otras dinámicas se concentraron en actos de presencia anual, como el stand de Chile en las Festas del Treball de 1979, con la recolección de firmas para denunciar la violación de los derechos humanos y charlas explicativas sobre el desarrollo de la semana del boicot contra Chile ${ }^{81}$. Algo similar se repitió en la fiesta de 1980, con presencia de una delegación chilena en el marco del certamen, aunque sin presencia de stands ni de discursos, los que estuvieron concentrados en delegados de otros países como Angola, Nicaragua y Palestina ${ }^{82}$.

\footnotetext{
75 ANC, fondo PSUC, JCC, Comitè executiu, Comunicat de prensa, Joventut Comunista de Catalunya (JCC). Comunicados de prensa, 1976-1978, 22 de octubre de 1978, caja 80, c. 1.

76 AHCO-C, op. cit., p. 7.

77 Idem.

${ }_{78} \mathrm{Ibid}$, p. 5.

79 'Xile: les coses comencen a canviar", Treball, 6 al 10 de septiembre de 1979, p. 14.

80 "Solidaritat amb Xile", Treball, 6 al 10 de septiembre de 1979, p. 13.

81 "La Festa de Treball, també solidària", Treball, 20 al 26 de septiembre de 1979, p.14.

82 "La Festa, oberta al món”, Treball, 25 de septiembre al 1 de octubre de 1980, p. 15.
} 
En este intertanto, la JCC estuvo centrada en un proceso de discusión interna respecto a su papel a nivel político y social como organización juvenil. A partir de la IV conferencia de 1978 y la dilación del II congreso, se visualizaron frentes de crítica en torno a cómo desarrollar las propuestas e ideas de la JCC y en la baja asistencia a instancias interpartidistas de debate con el PSUC por parte de los militantes juveniles ${ }^{83}$. Esto se amplió al ámbito electoral y la forma de acción como parte de un movimiento juvenil que estaba en un punto de pocos avances por el estancamiento del movimiento estudiantil desde el fin del franquismo ${ }^{84}$, la poca presencia de dirigentes obreros en la JCC y la falta de acción ante el mundo del trabajo ${ }^{85}$. Sin embargo, la crisis de la JCC se puede explicar en diversos ejes. En primer lugar, por el cambio político y social dado en la transición a la democracia, desde una sociedad civil antifranquista activa a la responsabilidad en las nuevas instituciones políticas, donde el rupturismo de la militancia comunista desde su activo antifranquismo dejó de ser un punto de referencia en la juventud catalana. En segundo lugar, y relacionado con lo anterior, la pérdida de militantes fue una expresión de esta crisis de representatividad juvenil. En términos numéricos, entre el I y II congreso de la JCC (1977 a 1980), la militancia bajó en un $78 \%$, pese a la presencia en municipios y en contextos de institucionalidad juvenil como el recién creado Consell Nacional de Joventut de Catalunya ${ }^{86}$.

De esta manera, la configuración de políticas de solidaridad explícitas con la causa chilena era de difícil expresión. La crisis interna de la JCC puede explicar en parte por qué fue el PSUC quien mantuvo, en descenso, la hegemonía de apoyos con Chile durante los años finales de la década de 1970. Pero otro factor que también sirve para entender la disminución de actividades corresponde a las diferencias teóricas entre el comunismo catalán y el chileno, las que iban por caminos separados. Como ya se ha explicado anteriormente, el PSUC siguió desde la muerte de Franco la línea eurocomunista -salvo el paréntesis 1981/1982-, con énfasis en los llamados a la unidad de las fuerzas políticas de izquierda y a la idea de solidaridad entre los pueblos a nivel de relaciones internacionales. Sin embargo, las posturas del comunismo chileno apuntaron en un camino distinto, en dejar de lado la idea de la unidad en un frente antifascista que no consideraba el uso legítimo de la violencia en la resistencia contra Pinochet ${ }^{87}$. La nueva opción se basó en el desarrollo de una política militar y de rebelión popular de masas, aplicado en la importancia de "todas las formas de lucha" en el derecho a rebelión contra un gobierno tiránico ${ }^{88}$, con elementos militares formados en el ejército cubano y experiencia en la guerrilla sandinista ${ }^{89}$, justificada por el secretario general del PCCh, Luis Corvalán, quien afirmó que el pueblo "no tendrá otro camino que recurrir a todos los medios a su alcance, a todas las formas de combate que le ayuden, incluso de violencia aguda, para defender su derecho al pan, a la libertad, a la vida" ${ }^{\prime \prime}$.

Así, la nueva línea chilena era marcadamente insurreccional, alejada del electoralismo, con cercanías con el internacionalismo proletario dada la formación de cuadros militares en países socialistas, pero por, sobre todo, marxista-leninista en su comprensión del comunismo, distante de la postura hegemónica en

83 Domènech Sampere, op. cit., p. 189.

${ }^{84}$ Josep María Colomer, Els estudiants de Barcelona sota el franquisme. vol 2, Barcelona, Curial, 1978, pp. 135-136; Eduardo González Callejas, Rebelión en las aulas. Movilización y protesta estudiantil en la España Contemporánea (1865-2008), Madrid, Alianza Editorial, 2009, pp. 353-354.

85 Domènech Sampere, op. cit., p. 190.

86 Ibid, p. 200.

${ }^{87}$ Claudio Pérez Silva, “Del 'vacío histórico' al desarrollo de la política militar del Partido Comunista de Chile. Itinerario y producción política de oficiales comunistas chilenos en las Fuerzas Armadas Revolucionarias de Cuba, 1975-1980", Trocadero. Revista de bistoria moderna y contemporánea, 29, Cádiz, p. 90, consultado en https://revistas.uca.es/index.php/trocadero/article/download/4103/3836

88 Rolando Álvarez, Desde las sombras. Una historia de la clandestinidad comunista (1973-1980), Santiago de Chile, LOM editores, 2003, p. 215.

89 Pérez Silva, op. cit., pp. 92.

90 Discurso del secretario general del PCCh, Luis Corvalán, en Moscú el 3 de septiembre de 1980, citado por Álvarez, op. cit., p. 216. 
el PCE-PSUC a fines de los setenta. Esto fue planteado por el miembro de la dirección general del PCCh, Volodia Teitelboim, a la revista Treball, al ser consultado ante conceptos del eurocomunismo como el socialismo en libertad, señalando:

\begin{abstract}
Sí, es una cuestión delicada, pero trataré de contestarlo. Mire, nosotros no somos eurocomunistas, entre otras cosas porque no somos europeos. Nosotros nos sentimos marxistas, nos sentimos leninistas, pero entendemos que ninguno puede pensar por otro partido, y que la aplicación de las leyes de la revolución fracasarán, si no pasa por una acertada interpretación de la realidad nacional y del contexto internacional (...) La realidad de Chile continúa siendo la cosa más importante, y la mayoría del partido trabaja en el país. Ahora, como usted ha dicho, tenemos comunistas chilenos afuera, dispersos por cuarenta países y organizados en treinta y cinco de ellos. Están respirando el aire de otras realidades nacionales y esto no es un hecho lesivo sino una posibilidad de ver nuestro propio problema con ojos más universales y abiertos. ${ }^{91}$
\end{abstract}

Si bien Teitelboim marcó un respeto ante estas posturas y los aprendizajes para los militantes comunistas chilenos, dejó en claro el carácter marxista-leninista del PCCh y su lejanía con el eurocomunismo. Esta última idea la avaló Luis Corvalán, quien destacó los elementos comunes entre la experiencia chilena del comunismo durante la UP por la llamada "vía pacífica" al socialismo y las ideas eurocomunistas, pero marcó las diferencias existentes respecto a las relaciones con la Unión Soviética y el abordaje sobre relación dictadura del proletariado y democracia entre ambas posturas ${ }^{92}$. Para el PCCh, la cercanía a la URSS y la dictadura del proletariado eran centrales, mientras que para los eurocomunistas no, siendo otro de los espacios de lejanía entre las posturas comunistas.

De esta forma, la vía comunista de solidaridad, en los marcos del eurocomunismo, entró en una pérdida de protagonismo de expresiones políticas y públicas a fines de la década de 1970. Esto marcó el declive de la hegemonía del comunismo catalán con Chile, tanto por la crisis interna de la JCC como por las diferencias teóricas antes explicadas. Pese a esto, otros grupos y movimientos juveniles expresaron durante este período, de manera menos sistemática, sus apoyos a Chile, especialmente desde el mundo de la izquierda y el catolicismo juvenil, además de expresiones adultas en sintonía con la situación chilena en otros ámbitos.

\title{
Conclusiones
}

La conformación de apoyos solidarios con Chile entre 1973 y 1980 desde las formaciones políticas catalanas estuvo marcada de forma clara por el rol hegemónico del PSUC y la JCC en las acciones desarrolladas durante estos años. Principalmente, dado el peso organizativo del comunismo catalán y el impacto de su legalización desde 1977, además de la influencia de sus posturas ante la solidaridad internacional.

En una primera instancia, especialmente desde la clandestinidad, las posiciones tendientes al internacionalismo proletario fueron las rectoras, fundamentalmente en los meses posteriores al golpe de Estado de 1973. Es llamativo el discurso directo y de carácter revolucionario, pero que está dentro de un contexto interno de ilegalidad y clandestinidad, en el que la derrota de la experiencia socialista chilena tuvo un fuerte impacto para el mundo comunista catalán, en una doble dimensión: el recuerdo de la Guerra Civil y el impacto de la derrota de una posibilidad democrática de socialismo. Sin embargo, el avance de las posturas eurocomunistas, entrecruzadas también por el tema de la nacionalidad catalana,

91 "Teitelboim: el repte de la unitat", Treball, 14 al 20 de febrero de 1980, p. 18.

${ }^{92}$ Luis Corvalán, De lo vivido y lo peleado. Memorias, Santiago de Chile, LOM editores, 1997, p. 273. 
incidieron en la moderación de las posturas hacia la solidaridad de los pueblos como concepto de apoyo internacional con el comunismo chileno y otros movimientos afines.

Por otro lado, el desarrollo de la transición española y la conformación de las posturas de la ruptura democrática que encabezaba el comunismo español y catalán, implicó el explicitar el entendimiento de cómo debía ser un sistema democrático, pluralista y abierto. El reconocimiento del PSUC-JCC a las ideas de libertad y la necesidad de revisar el tema nacional desde la autonomía, implicaron un trabajo político público para el desarrollo de estas ideas y de cómo entender la democracia a construir. En ese sentido, el apoyo a países que estaban en dictadura, como el caso chileno, era un mecanismo de expresión respecto a dónde no retornar como vivencia política, sumado al desarrollo de una política internacional alejada del intervencionismo, en el respeto de la autodeterminación y el respeto por los derechos humanos.

Estos ámbitos y posturas desarrollados por el comunismo catalán incidieron en la solidaridad con Chile y generaron, especialmente en lo juvenil, una serie de acciones de apoyo. La Festa de Jovent o el estand de la JCC en las Festas de Treball fueron espacios para demostrar la cooperación y preocupación respecto a Chile, además de las invitaciones a congresos, ponencias o los espacios informativos en la prensa comunista. Todos estos ámbitos, en general, se expresaron en espacios políticos marcados de reuniones y acuerdos, sin ocupar el espacio público, sino aprovechando situaciones partidistas e institucionales para demostrar la cooperación. Por otro lado, esta solidaridad estaba relacionada generalmente con el comunismo chileno más que con la oposición chilena en su conjunto, salvo cuando las acciones fueron coordinadas con otros grupos políticos a nivel adulto o en la transversalidad de actos, como la Conferencia Mundial de Solidaridad con Chile realizada en Madrid en 1978, con presencia del PSUC y el rol activo de la JCC en la participación en el espacio juvenil de este encuentro.

Sin embargo, el descenso participativo de la JCC, demostrada en la crisis de militantes, el fortalecimiento del eurocomunismo dentro del PSUC y la lejanía con las posturas chilenas ante cómo derrocar la dictadura de Pinochet, marcaron la brusca disminución de los apoyos solidarios para fines de la década estudiada. Las proyecciones no serán halagüeñas para los años ochenta, donde la crisis del comunismo catalán y español tuvo su zénit en 1982, con el quiebre entre eurocomunistas y prosoviéticos, el desmembramiento del PSUC y del PCE hasta la formación de la Izquierda Unida en 1986. Por ende, el fin de la hegemonía comunista en la solidaridad con Chile se explica por estas fracturas internas, pero sin tener un impacto en estas acciones durante la década de 1980, las que se mantuvieron de forma constante con la presencia de nuevos actores políticos ante esta demand $a^{93}$.

\section{Bibliografía}

\section{Impresas}

Rolando Álvarez, Desde las sombras. Una historia de la clandestinidad comunista (1973-1980), Santiago de Chile, LOM editores, 2003.

Josep María Colomer, Els estudiants de Barcelona sota el franquisme. Vol 1, Barcelona, Curial, 1978.

Luis Corvalán, De lo vivido y lo peleado. Memorias, Santiago de Chile, LOM editores, 1997.

93 Véase Pedro Marchant, Solidaridad política juvenil barcelonesa por la democracia en Chile (1976-1990), (Tesis de máster), Barcelona, Universitat de Barcelona, 2018, pp. 63-85. 
Xavier Domènech Sampere, Temps d'interseccions. La Joventut Comunista de Catalunya (1970-1980), Barcelona, Fundació Francesc Ferrer i Guàrdia, 2008.

Elena Hernández, et. al, Estudiantes contra Franco (1939 - 1975). Oposición politica y movilización juvenil, Madrid, La Esfera de los Libros, 2007.

Pedro Marchant, Solidaridad politica juvenil barcelonesa por la democracia en Cbile (1976-1990), (Tesis de máster), Barcelona, Universitat de Barcelona, 2018.

Andreu Mayayo i Artal, La ruptura catalana, Barcelona, Editorial Afers, 2002

Carme Molinero y Pere Ysàs, La cuestión catalana. Cataluña en la transición española, Barcelona, Crítica, 2014.

Mario Olguín, "Exilio político chileno en España (1973-1990/1994). El caso de Zaragoza. Acercamiento al estudio, avances y discusiones de la investigación", Carlos Forcadell y Carmen Frías (eds), X Congreso de Historia local en Aragón, Zaragoza, Institución Fernando el Católico, 2017, pp. 401-412.

Carles Santacana (moderador), "Les organitzacions polítiques juvenils" (mesa redonda), Rafael Aracil, Andreu Mayayo y Antoni Segura (eds), Memòria de la transició a Espanya i Catalunya. Els joves de la Transició, vol. IV, Barcelona, Edicions Universitat de Barcelona, 2003, pp. 219-264.

Antoni Segura i Mas, "Memòria i Història de la transició", Rafael Aracil y Antoni Segura, (eds), Memòria de la transició a Espanya i a Catalunya, Barcelona, Edicions Universitat de Barcelona, 2000, pp. 11-66.

\section{Archivos}

Arxiu Nacional de Catalunya: Fondo Partit Socialista Unificat de Catalunya. Arxiu Biblioteca del Pavelló de la República de la Universitat de Barcelona. Arxiu Històrico de las Comisiones Obreras de Catalunya: Fondo digital.

\section{Hemerotecas}

Avui.

El País.

La Vanguardia / La Vanguardia Española.

Jove Guàrdia

Jovent.

Treball.

\section{Fuentes electrónicas}

Elías Álvarez Justo, El Eurocomunismo y su influencia en el PCE y el PSUC, (tesis de máster) Barcelona Universidad de Barcelona, 2018, consultado en http://hdl.handle.net/2445/126727 [acceso 22 de junio de 2019].

Perry Anderson, "Internacionalismo: un breviario", New Left Review 14, Madrid, 2002, pp. 5 - 24, consultado en http://newleftreview.es/article/download pdf?id=2376\&language=es [acceso 17 de julio de 2018].

Pere Anguera, "El 11 de septiembre. Orígenes y consolidación de la Diada", Ayer, 51, Madrid, 2003, pp. 1738 , consultado en 
http://revistaayer.com/sites/default/files/articulos/51-1-ayer51 DiasEspana Anguera.pdf [acceso 25 de junio de 2019].

Andrea Donofrio, "El final del eurocomunismo y el Partido Comunista de España (PCE)", Studia Histórica Historia Contemporánea, 31, Salamanca, 2013, pp. 167-191, consultado en http://revistas.usal.es/index.php/0213-2087/article/view/14597/15051 [acceso 22 de junio de 2019].

Friedrich Engels, "Prefacio a la edición inglesa de 1888", Karl Marx y Friedrich Engels, Manifiesto del Partido Comunista, Madrid, Fundación de Investigaciones Marxistas, 2013, consultado en www.pce.es/descarga/manifiestocomunista.pdf. [acceso 18 de julio de 2018].

Antoni Lardín i Oliver, "La organización clandestina del PSUC en Cataluña en los años cincuenta", Hispania Nova 5, Madrid, 2005, pp. 27 - 43, consultado en http://hispanianova.rediris.es/5/articulos/5a002.htm [acceso 20 de junio de 2019].

Joan Marcet et al, “Aproximación a la sociología de los partidos políticos catalanes", Revista de Estudios Políticos 10, Madrid, 1979, pp. 143-206, consultado en https://dialnet.unirioja.es/descarga/articulo/1273230.pdf [acceso 17 de julio de 2018].

Domènec Martínez, "Intervencions de diferents protagonistas de la JCC”, Fundació Nous Horitzons, 35è aniversari de la constitució del Comitè Nacional de la Joventut Comunista de Catalunya, Barcelona, Fundació Nous Horitzons, 2005, pp. 10 - 15, consultado en http://www.noushoritzons.cat/ca/file/156002/download?token=ybzhoMgD [acceso 17 de julio de 2018].

Héctor Opazo Romero, Los actores no gubernamentales españoles ante el régimen militar de Augusto Pinochet (1973-1990): Apoyo a la democratización y defensa de los derechos humanos, (tesis doctoral), Madrid, Universidad Complutense de Madrid, 2008, consultado en http://eprints.ucm.es/8798/ [acceso 9 de julio de 2018].

Partit Socialista Unificat de Catalunya, Estatuts del Partit Socialista Unificat de Catalunya. IV congreso (1977), Barcelona, PSUC, 1977, consultado en http://biblioteca.andalucia.ccoo.es:8080/intranettmpl/prog/local repository/documents/14948 6696.pdf. [acceso 17 de julio de 2018].

Claudio Pérez Silva, "Del 'vacío histórico' al desarrollo de la política militar del Partido Comunista de Chile. Itinerario y producción política de oficiales comunistas chilenos en las Fuerzas Armadas Revolucionarias de Cuba, 1975-1980", Trocadero. Revista de historia moderna y contemporánea, 29, Cádiz, pp. 81 - 115, consultado en https://revistas.uca.es/index.php/trocadero/article/download/4103/3836 [acceso 20 de julio de 2018].

Margaret Power y Julie A. Charpil, "Introduction: On solidarity", Latin American Perspectives 6: 36, Riverside, 2009, pp. 3 - 9, disponible en https://www.jstor.org/stable/20684682 [acceso 16 de agosto de 2018].

Sally J. Scholz, Political Solidarity, University Park, Pennsylvania State University Press, 2008, disponible en https:/ / books.google.es/books?id=lV10UTD53E0C\&pg=PT27\&hl=es\&source=gbs toc $\mathrm{r} \& \mathrm{cad}=3 \#_{\mathrm{v}}=$ on epage\&q\&f=false [acceso 16 de agosto de 2018]. 